\section{Judgments of Power From College Yearbook Photos and Later Career Success}

\author{
Nicholas O. Rule' and Nalini Ambady ${ }^{2}$
}

Social Psychological and

Personality Science

2(2) 154-I58

(C) The Author(s) 2011

Reprints and permission:

sagepub.com/journalsPermissions.nav DOI: 10.1 177//9485506/0385473 http://spps.sagepub.com

(SAGE

\begin{abstract}
Inferences from faces can predict important real-world outcomes. But little is known about the stability of these effects. Here the authors find that inferences of power from photos of the faces of the managing partners of America's top 100 law firms significantly corresponded to their success as leaders, as measured by the amounts of profits that their firms earned. More interesting, this relationship was also observed when judgments were made based on photos of the leaders taken from their undergraduate yearbooks, before they began their careers or entered law school. Facial cues to success may therefore be consistent across much of the lifespan (approximately $20-50$ years).
\end{abstract}

\title{
Keywords
}

impression management, leadership, nonverbal behavior, person, perception, personality

Faces affect impressions of individuals throughout the lifespan and influence others' behavior. Facial appearance has been found to affect individuals' employment opportunities (Collins $\&$ Zebrowitz, 1995), their levels of success within particular jobs (Stevenage \& McKay, 1999), and their outcomes in court (Zebrowitz \& McDonald, 1991). One study (Mueller \& Mazur, 1996) found that judgments of dominance from the faces of some high-achieving West Point cadets predicted whether they became generals. In another study, judgments of power from the faces of chief executive officers (CEOs) of Fortune 1,000 companies predicted their actual success as leaders, as measured by the amounts of profits that their companies earned (Rule \& Ambady, 2008). In the present work, we examined whether judgments of personality from facial cues in young adulthood were related to career outcomes later in life.

Early characteristics can predict important later life outcomes. In a host of studies, Caspi and colleagues have found that children's personality and behavior have effects on their social behavior (Caspi, 2000), health (Caspi, Harrington, Moffitt, Milne, \& Poulton, 2006), socioeconomic status (Poulton et al., 2002), and work performance (Roberts, Harms, Caspi, \& Moffitt, 2007) in adulthood, with effects reaching as far as the molecular functioning of the individuals' immune systems (Danese, Pariante, Caspi, Taylor, \& Poulton, 2007). Similarly, children's standardized test scores have shown surprising levels of predictive value for their life outcomes in terms of success and creativity, particularly among those earning scores within the 99th percentile (Lubinski \& Benbow, 2006). These longitudinal studies have employed multivariate self-reports, which provide a great deal of information about the participants' relationships, personalities, and social environments; but other studies with a more focused set of predictors have shown similar effects. Harker and Keltner (2001) found that the degree to which women smiled in their college yearbook photographs predicted their well-being and marital satisfaction later in life, and Hertenstein, Hansel, Butts, and Hile (2009) expanded this to show that the extent of smiling in photographs from childhood predicted whether individuals were likely to be divorced. All of these studies show that personality - that is, individuals' ways of approaching and responding to the world (Caspi, 1987) — tends to be fairly stable over the life course (Caspi et al., 2003). Not only personality but also structural aspects of facial appearance (attractiveness and facial maturity) have also been found consistent in individuals across time (Zebrowitz, Olson, \& Hoffman, 1993).

Although some judgments of personality from appearance early in life show evidence of consistency with judgments later in life (Zebrowitz, Collins, \& Dutta, 1998) and such judgments have been found to predict well-being, little is known about which other aspects of individuals' lives relate to their appearance in youth. The current study, therefore, examined the relationship between trait impressions of leaders based on photographs taken in early adulthood before they started their careers or began training in the field of their later leadership. These judgments were compared to judgments made from

\footnotetext{
'University of Toronto, Ontario, Canada

${ }^{2}$ Tufts University, Medford, MA, USA

Corresponding Author:

Nicholas O. Rule, University of Toronto, 100 St. George Street, Toronto, ON, M5S 3G3

Email: rule@psych.utoronto.ca
} 
current photographs of the leaders and related to an objective measure of their success as leaders: the profits earned by their organizations. Thus, participants rated the current and college yearbook photos of the managing partners (MPs) of America's top 100 law firms. MPs of law firms are similar to companies' CEOs. But unlike many CEOs, MPs rarely find their positions through external hiring. MPs advance through the ranks of the law firm and acquire their positions by vertical promotion. This necessitates that MPs have the base set of skills and legal training required to first get hired at a particular firm and to later be successful in the work performed at the lower ranks, although much of the work that takes place for MPs in their early days is not that of leadership per se.

\section{Method}

\section{Stimuli}

Headshot photographs of the MPs of each of the firms from the American Lawyer's top 100 firms for 2007 (AmLaw 100:2007; see http://www.law.com) were downloaded from their firm's Web sites. Current photos for 8 of the firms' leaders could not be retrieved, for a total of 92 targets. In addition, undergraduate yearbook photos from each MPs graduation year were digitally scanned from their respective college yearbooks. We were able to obtain photos for 73 of the 92 targets, spanning 43 different universities. Mean latency since undergraduate graduation was 33 years $(S D=6$ years; range $=21-49$ years $)$.

Each photograph was standardized by cropping the image to the extremes of the head: the top of the hair, the bottom of the chin, and the limits of the ears or hair. Thus, no clothing was visible in any of the photographs. In addition, each photo was converted to grayscale and standardized in size.

Information about each MP's firm was acquired from the AmLaw 100:2007 listing, including profit margin, profitability index, profits per equity partner (PPP), and the number of lawyers in each firm, among other variables. Of these, we were principally interested in measures of profits for use as dependent variables.

\section{Procedure}

In exchange for partial course credit, 67 undergraduates were randomly assigned to rate either the current photos $(n=35)$ or the college yearbook photos $(n=32)$ of the MPs. The experiment consisted of four blocks. In each block, participants saw all 73 faces (either the current or yearbook photos) presented in random order. The order of the blocks was random, and each block consisted of a different trait judgment: dominance, facial maturity, likeability, and trustworthiness (Rule et al., 2010). Each trait was rated along a 7-point scale, anchored at 1 (not at all $x$ ) and 7 (very $x$; all Cronbach's $\alpha$ s $>$.81). After completing the experiment, participants were asked whether they had recognized any of the faces; none did.

Because of the influence of attractiveness (Dion, Berscheid, \& Walster, 1972) and emotional expression (Zebrowitz, Kikuchi, \& Fellous, 2010) on judgments of faces, separate
Table I. Factor Loadings and Variance Explained for Principal Components Analyses

\begin{tabular}{lccccc}
\hline & \multicolumn{2}{c}{ Current photos } & & \multicolumn{2}{c}{ Yearbook photos } \\
\cline { 2 - 3 } \cline { 5 - 6 } & Power & Warmth & & Power & Warmth \\
\hline Dominance & .71 & -.53 & & .85 & .06 \\
Facial maturity & .93 & .14 & & .84 & -.08 \\
Likeability & -.12 & .94 & & .08 & .97 \\
Trustworthiness & .05 & .96 & & -.10 & .96 \\
Variance explained (\%) & 35 & 53 & & 36 & 47 \\
\hline
\end{tabular}

groups of blind coders provided ratings of attractiveness (yearbook photos: $n=10$, Cronbach's $\alpha=.89$; current photos: $n=$ 15 , Cronbach's $\alpha=.70$ ) and affect (yearbook photos: $n=9$, Cronbach's $\alpha=.95$; current photos: $n=10$, Cronbach's $\alpha=.89$ ) for use as covariates in the analysis. In addition, to control for differences based on approximate age and years of experience, each MP's year of graduation from law school was subtracted from the listing's fiscal year (2006) and entered as a covariate in the analysis. Finally, to control for firm size, the number of lawyers working in the firm (as based on the AmLaw 100 listing information) was used as a covariate as well.

\section{Results}

Ratings of the targets in their college yearbook and current photos were relatively consistent across time. Ratings of dominance, $r(71)=.25, p=.03$, likeability, $r(71)=.27, p=.02$, and trustworthiness, $r(71)=.35, p=.003$, were significantly correlated across the two conditions. However, participants' ratings of facial maturity were not significantly correlated, $r(71)=.06, p=.63$, nor were the separate raters' judgments of attractiveness, $r(70)=.03, p=.81$, or affect, $r(71)=.07$, $p=.53$.

The participants' trait ratings were subjected to principal components factor analyses with varimax rotation (see Table 1). For both the current and yearbook photos, ratings of dominance and facial maturity were averaged to form a power composite and ratings of likeability and trustworthiness were averaged to form a warmth composite.

The power and warmth scores were then correlated with the dependent variables of profit margin, profitability index, and PPP while controlling for the influence of facial attractiveness, affect, number of lawyers per firm, and MP years of experience. Where necessary, variables were transformed using the natural logarithm to achieve normality and outliers greater than three standard deviations from the mean were removed, resulting in the exclusion of eight of the targets from the current photos and seven of the targets from the yearbook photos. ${ }^{1}$

For the current photos, power was positively correlated with profit margin, $r(59)=.31, p=.02$, profitability index, $r(59)=$ $.32, p=.01$, and PPP, $r(59)=.38, p=.003$, whereas none of these indices was related to warmth (see Table 2). Similarly, for the yearbook photos, power was again positively correlated 
Table 2. Correlations Between Ratings of Power and Warmth From Yearbook Photos (Above the Diagonal) and Current Photos (Below the Diagonal) With Firm Profits, as Measured by Profit Margin, Profitability Index, and Profits per Partner (PPP), While Controlling for Affect, Attractiveness, Managing Partner Years of Experience, and Number of Lawyers per Firm

\begin{tabular}{lccccc}
\hline & 1 & 2 & 3 & 4 & 5 \\
\hline I. Power & & -.21 & $.27^{*}$ & $.25^{*}$ & $.22 \dagger$ \\
2. Warmth & -.10 & & $-.32^{* *}$ & -.14 & -.19 \\
3. Profit margin & $.31^{*}$ & -.09 & & $.58^{* * *}$ & $.67^{* * *}$ \\
4. Profitability index & $.32^{*}$ & -.22 & $.56^{* * *}$ & & $.92^{* * *}$ \\
5. PPP & $.38^{* *}$ & -.20 & $.66^{* * *}$ & $.92^{* * *}$ &
\end{tabular}

${ }^{\dagger} p<.09$.

$* p<.05$.

$* * p<.01$.

$* * * p<.001$

with profit margin, $r(60)=.27, p=.04$, profitability index, $r(60)=.25, p=.05$, and PPP, $r(60)=.22, p=.09$, though this last relationship was only marginally significant. Warmth was again unrelated to profitability index and PPP $(r \mathrm{~s}<|.19|, p \mathrm{~s}>$ $.15)$ but did show a significant negative relationship with profit margin, $r(60)=-.32, p=.01$.

\section{Discussion}

Judgments from both current and college yearbook photos predicted leaders' success, as measured by their firms' profits. Firms' profits are typically regarded as the "gold standard" of an organization's performance, providing a strong indication of an individual's ability as a leader (Kaiser, Hogan, \& Craig, 2008). Specifically, inferences of power from the faces of law firm MPs predicted the amounts of profits that their firms earned. These relationships were consistent for current photos and for photos taken roughly 20 to 50 years earlier. The aspects of the face that are predictive of these leaders' success therefore appear to be consistent across time rather than developed through experience.

These results are particularly noteworthy given the homogeneity among the targets' yearbook photos. Unlike the MPs' current photos, the college yearbook photos were much less susceptible to self-presentation biases that might occur in photographs released by law firms. For instance, MPs and their firms' public relations advisors may wish to present a firm's leader in a particular way, or more successful firms may hire better photographers. In addition, although the MPs in the law firm photographs varied in age, they were all approximately the same age in the yearbook photos taken in their senior year of college. Moreover, these effects emerged even when removing the influence of important secondary variables, such as emotional expressions, facial attractiveness, the MPs' years of experience, and the size of the MPs' firms.

Our findings highlight the importance of power as judged from the face in predicting professional success. In U.S. culture, dominance and power are strongly associated with perceived leadership abilities as well as with leadership performance outcomes (Rule \& Ambady, 2008; Rule et al., 2010). The present data show not only that these perceptions may correspond with actual ability but also that the seeds of the relationship between perceptions and performance are evident early on; that is, the perceptions can predict the outcomes before the task begins. Moreover, although all of the MPs of America's 100 best law firms can be considered successful, perceptions of power from their faces distinguished their degree of success relative to one another. Perceived power not only might therefore be important for obtaining a leadership position but also may correspond to one's success within a leadership position.

Previous research has shown that appearances can influence individuals' own traits and behaviors via expectancyconfirmation processes. For instance, teachers' expectations influence students' progress in school: Students whom teachers expect to perform better may actually perform better because the teachers give them more attention and provide them with more opportunities for success (Rosenthal, 1994; Rosenthal \& Jacobsen, 1968). Similarly, attractive infants are treated more warmly by their parents (Langlois, Ritter, Casey, \& Sawin, 1995), which may cause them to become warmer adults (Trzesniewski et al., 2006). In addition, appearances can lead individuals to select particular environments and activities, which might then lead them to develop stereotype-congruent patterns of behavior (Caspi et al., 2006; Zebrowitz, 1997). Thus, in the domain of leadership, individuals who look like better leaders could actually become better leaders because they are more often chosen for leadership positions, are more likely to be treated like leaders by their peers and mentors, and are given more opportunities to develop leadership abilities.

This work has some limitations. First, these data pertain to a specific set of individuals who have attained a high level of success. It is unknown whether perceptions of these same traits from these individuals' undergraduate classmates, for example, would also predict their success or if these effects are restricted to particular individuals within a particular domain. Along these lines, it is important to note that the participants' perceptions of power explained approximately $14 \%$ of the variance in the MPs' success. Although this is a significant portion of variance, clearly numerous other variables also shape these outcomes.

Similarly, although the relationship between judgments of the MPs' faces with their current success as leaders was consistent across time, this may vary in other domains. There is much evidence suggesting that life experiences influence the development of facial appearance (Malatesta, Fiore, \& Messina, 1987; Zajonc, Adelmann, Murphy, \& Niedenthal, 1987), and the present findings should not be interpreted as suggesting that facial appearance is the sole determinant of one's life outcomes. Rather, it seems more likely that innate appearance and life experiences work in concert to shape facial appearance in a way that predicts outcomes. Indeed, one limitation of the present work is that the photos were taken from college yearbooks, well into the individuals' psychological and physical development. It therefore remains possible that early appearance 
effects (Clifford \& Walster, 1973) and experiences may also have an important influence on appearance and subsequent behavior. Further research is needed to disentangle how innate and experiential factors contribute to the development of appearance in this context.

Finally, both participants' judgments and the targets' outcomes were indirectly related to leadership. Participants judged personality traits that are highly relevant to leadership ability (e.g., Kaplan, Klebanov, \& Sorensen, 2008) but that do not directly measure a perceiver's opinion of an individual's capacity as a leader. Similarly, although profits are the most robust measure of a financial institution's success (Kaiser et al., 2008), they are not direct measures of the management ability of its leader. The indirect nature of these relationships may be limitations to the present work but might also be advantages, as direct judgments may sometimes be less accurate than indirect judgments (Rule \& Ambady, 2008). Future work may wish to explore this question in more detail.

In sum, there seems to be consistency in judgments of personality from photographs of faces in early and later adulthood with a span of approximately 20 to 50 years between the two sets of photographs. Moreover, judgments of power from individuals' faces in young adulthood predicted their professional success an average of 33 years later, and judgments of power from faces in later photographs were also related to success. The elements of facial appearance that predict some individuals' professional success may therefore be consistent across time.

\section{Declaration of Conflicting Interests}

The authors declared no potential conflicts of interests with respect to the authorship and/or publication of this article.

\section{Financial Disclosure/Funding}

This research was supported in part by a National Science Foundation Graduate Research Fellowship and Canada Research Chair award to NOR and National Science Foundation grant BCS-0435547 to NA.

\section{Note}

1. The affect ratings of the yearbook photos could not be transformed to achieve normality, and so the nearest to normal transformation was used. Notably, the results did not substantially differ when the affect variable was excluded from the analysis.

\section{References}

Caspi, A. (1987). Personality in the life course. Journal of Personality and Social Psychology, 53, 1203-1213.

Caspi, A. (2000). The child is father of the man: Personality continuities from childhood to adulthood. Journal of Personality and Social Psychology, 78, 158-172.

Caspi, A., Harrington, H., Milne, B., Amell, J. W., Theodore, R. F., \& Moffitt, T. E. (2003). Children's behavioral styles at age 3 are linked to their adult personality traits at age 26. Journal of Personality, 71, 495-513.

Caspi, A., Harrington, H., Moffitt, T. E., Milne, B. J., \& Poulton, R. (2006). Socially isolated children 20 years later: Risk of cardiovascular disease. Archives of Pediatric and Adolescent Medicine, 160, 805-811.

Clifford, M. M., \& Walster, E. H. (1973). The effect of physical attractiveness on teacher expectations. Sociology of Education, 46, 248-258.

Collins, M. A., \& Zebrowitz, L. A. (1995). The contributions of appearance to occupational outcomes in civilian and military settings. Journal of Applied Social Psychology, 25, 129-163.

Danese, A., Pariante, C. M., Caspi, A., Taylor, A., \& Poulton, R. (2007). Childhood maltreatment predicts adult inflammation in a life-course study. Proceedings of the National Academy of Sciences of the USA, 104, 1319-1324.

Dion, K., Berscheid, E., \& Walster, E. (1972). What is beautiful is good. Journal of Personality and Social Psychology, 24, 285-290.

Harker, L., \& Keltner, D. (2001). Expressions of positive emotion in women's college yearbook pictures and their relationship to personality and life outcomes across adulthood. Journal of Personality and Social Psychology, 80, 112-124.

Hertenstein, M. J., Hansel, C. A., Butts, A. M., \& Hile, S. N. (2009). Smile intensity in photographs predicts divorce later in life. Motivation and Emotion, 33, 91-105.

Kaiser, R. B., Hogan, R., \& Craig, S. B. (2008). Leadership and the fate of organizations. American Psychologist, 63, 96-110.

Kaplan, S. N., Klebanov, M. M., \& Sorensen, M. (2008, July). Which CEO characteristics and abilities matter? Paper presented at the annual meeting of the American Financial Association, New Orleans, LA.

Langlois, J. H., Ritter, J. M., Casey, R. J., \& Sawin, D. B. (1995). Infant attractiveness predicts maternal behaviors and attitudes. Developmental Psychology, 31, 464-472.

Lubinski, D., \& Benbow, C. P. (2006). Study of mathematically precocious youth after 35 years: Uncovering antecedents for the development of math-science expertise. Perspectives on Psychological Science, 1, 316-345.

Malatesta, C. Z., Fiore, M. J., \& Messina, J. J. (1987). Affect, personality, and facial expression characteristics of older people. Psychology and Aging, 2, 64-69.

Mueller, U., \& Mazur, A. (1996). Facial dominance of West Point cadets as a predictor of later military rank. Social Forces, 74, 823-850.

Poulton, R., Caspi, A., Milne, B. J., Thomson, W. M., Taylor, A., Sears, M. R., \& Moffitt, T. E. (2002). Association between children's experience of socioeconomic disadvantage and adult health: A life-course study. Lancet, 360, 1640-1645.

Roberts, B. W., Harms, P. D., Caspi, A., \& Moffitt, T. E. (2007). Predicting the counterproductive employee in a child-to-adult prospective study. Journal of Applied Psychology, 92, 1427-1436.

Rosenthal, R. (1994). Interpersonal expectancy effects: A 30-year perspective. Current Directions in Psychological Science, 3, 176-179.

Rosenthal, R., \& Jacobsen, L. (1968). Pygmalion in the classroom: Teacher expectations and pupils' intellectual development. New York, NY: Holt, Rinehart \& Winston.

Rule, N. O., \& Ambady, N. (2008). The face of success: Inferences from chief executive officers' appearance predict company profits. Psychological Science, 19, 109-111. 
Rule, N. O., Ambady, N., Adams, R. B. Jr., Ozono, H., Nakashima, S., Yoshikawa, S., \& Watabe, M. (2010). Polling the face: Prediction and consensus across cultures. Journal of Personality and Social Psychology, 98, 1-15.

Stevenage, S. V., \& McKay, Y. (1999). Model applicants: The effect of facial appearance on recruitment decisions. British Journal of Psychology, 90, 221-234.

Trzesniewski, K. H., Donnellan, M. B., Moffitt, T. E., Robins, R. W., Poulton, R., \& Caspi, A. (2006). Low self-esteem during adolescence predicts poor health, criminal behavior, and limited economic prospects during adulthood. Developmental Psychology, 42, 381-390.

Zajonc, R. B., Adelmann, P. K., Murphy, S. T., \& Niedenthal, P. M. (1987). Convergence in the physical appearance of spouses. Motivation and Emotion, 11, 335-346.

Zebrowitz, L. A. (1997). Reading faces: Window to the soul? Boulder, CO: Westview.

Zebrowitz, L. A., Collins, M. A., \& Dutta, R. (1998). The relationship between appearance and personality across the lifespan. Personality and Social Psychology Bulletin, 24, 736-749.
Zebrowitz, L. A., Kikuchi, M., \& Fellous, J. M. (2010). Facial resemblance to emotions: Group differences, impression effects, and race stereotypes. Journal of Personality and Social Psychology, 98, 175-189.

Zebrowitz, L. A., \& McDonald, S. M. (1991). The impact of litigants' baby-facedness and attractiveness on adjudications in small claims courts. Law and Human Behavior, 15, 603-623.

Zebrowitz, L. A., Olson, K., \& Hoffman, K. (1993). Stability of babyfaceness and attractiveness across the life span. Journal of Personality and Social Psychology, 64, 453-466.

\section{Bios}

Nicholas O. Rule, $\mathrm{PhD}$, is assistant professor of psychology and Canada Research Chair in Social Perception and Cognition at the University of Toronto.

Nalini Ambady, $\mathrm{PhD}$, is professor of psychology and Neubauer Faculty Fellow at Tufts University. 